\title{
Author Correction: Revisiting the pH-gated conformational switch on the activities of HisKA- family histidine kinases
}

\author{
Cristina Mideros-Mora (D), Laura Miguel-Romero (D), Alonso Felipe-Ruiz (D), Patricia Casino (D) \& Alberto Marina (D)
}

Correction to: Nature Communications https://doi.org/10.1038/s41467-020-14540-5, published online 7 February 2020.

The original version of this Article omitted a reference to previous work in 'Chakraborty, S., Winardhi, R.S., Morgan, L.K., Yan, J. \& Kenney, L.J. Non-canonical activation of OmpR drives acid and osmotic stress responses in single bacterial cells. Nat. Commun. 8, 1587 (2017)'. This has been added as reference 29 after the fourth sentence in the Results paragraph ' $\mathrm{pH}$ Influence on the functional activities of EnvZ-OmpR': 'A substantial reduction in EnvZ autophosphorylation induced by lowering the pH (from 7.5 to 5.5) has also been demonstrated previously ${ }^{29}$.' This has been corrected in the PDF and HTML versions of the Article.

Published online: 19 May 2020

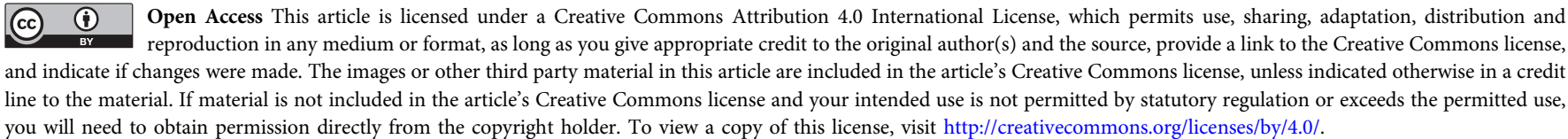

(c) The Author(s) 2020 